\title{
Assessing Freshwater Availability in Africa under the Current and Future Climate with Focus on Drought and Water Scarcity
}

\author{
$\underline{\text { H. Yang }}{ }^{a, b}$, M. Faramarzi ${ }^{b}$ and K. C. Abbaspour ${ }^{a, c}$ \\ ${ }^{a}$ Eawag, Swiss Federal Institute of Aquatic Science and Technology, P.O. Box 611, 8600 Dübendorf, \\ Switzerland. \\ ${ }^{b}$ Department of Environmental Sciences, University of Basel, Petersplatz, 1, 4003, Switzerland \\ ${ }^{c}$ Department of Natural Resources, Isfahan University of Technology, 84156 Isfahan, Iran. \\ E-mail: hong.yang@eawag.ch
}

\begin{abstract}
Droughts can have devastating effects on water supply, crop production, food security and many other aspects of human livelihood. The impact is particularly severe in Africa where subsistence farming dominates the food production and where political, social and economic systems are often inadequately prepared to cope with disasters. The recurrence of droughts in the past decades has triggered many famines in the continent. The severity of droughts and their impacts is projected to increase as a consequence of climate change. By applying a semi-distributed hydrological model SWAT (Soil and Water Assessment Tool), this study estimates the different freshwater components (i.e., green and blue water) for the whole African continent at the subbasin level. The spatial and temporal distributions of water resources are assessed. The presented model is then used to project the water resources availability under the future climate change in Africa for the period 2020-2040. Particular attention is made to the dry periods and their implications for water supply and food production. The simulation under the current climate shows that on a continental and annual basis, Africa has abundant water resources but the problem is the large spatial and temporal variability within and between African countries and river basins. The simulation of the impact of the future climate change on water resources is conducted with the projected climate data from 5 global circulation models (GCMs) under the four IPCC emission scenarios. The projected climate data are fed into the SWAT model calibrated under the current climate situation. The results show that for Africa as a whole, the mean total quantity of water resources is likely to increase. For individual subbasins and countries, variations are substantial. Although uncertainties are high in the simulated results, it is found that in many regions/countries, most of the climate scenarios projected the same direction of changes in water resources, suggesting a relatively high confidence in the projections. The assessment of the number of dry days and the frequency of their occurrences suggests an increase in the drought events and their duration in the future. This poses additional challenge to the agriculture in dry regions where water shortage is already severe while irrigation is expected to become more important to stabilize and increase food production.
\end{abstract}

Keywords: SWAT, water resources, drought, prediction uncertainty, climate change, Africa 


\section{INTRODUCTION}

Africa is home to 600 million people experiencing water scarcity (World Bank, 1995, IPCC 2007), and in the Sub-Saharan Africa alone over 260 million people are undernourished. Unreliable rainfall patterns, uneven distribution of water resources, weather variability, and human factors such as population growth and tensions over the shared waters present a significant concern for the availability, access, and utilization of water resources. This has a direct impact on the livelihoods of many, particularly the poor people in Africa (Boko, et al., 2007; Shongwe, 2009; Vörösmarty et al., 2010, Milly et al., 2005; Gaiser et al., 2011, Liu et al., 2008). Climate change and its impact on water resources availability in space and time have posed further challenges to the African countries in their aspiration to harness the water and improve food security. In the face of the climate change and deteriorating water availability as the key issues to the sustainability, the shared Africa Water Vision for 2025 and The New Partnership for Africa's Development call for new ways to assist countries in integrating climate change responses into their national development processes. There are many challenges in the continent in managing water resources with respect to drought, flood and climate change. To explore innovative approaches to meet the challenges, the information on seasonal and annual changes in water resources availability with explicit quantification of blue and green water components in the context of global change is necessary. Achieving such goal with a high spatial and temporal resolution will facilitate design and implementation of climate change adaptation and mitigation measures.

The main objective of this study is to quantify the mid-term impact of climate change on water resources in Africa at a subbasin spatial and monthly temporal scale. In the literature, the term "blue water" refers to the summation of the water yield and deep aquifer recharge which are renewable resources. Green water flow is defined as the actual evapotranspiration, and green water storage is the soil moisture (Falkenmark and Rockstrom, 2006). This study will present the results for the two components of the water resources. This information allows for a better water management and planning of future developments in Africa in the context of climate change. To achieve this goal, we have implemented an integrated hydrological simulation model at the continental level with the subbasin as the basic hydrological unit to study the net effect of climate change on hydrological water balance and water resources components. The time period of the investigation is from 2020 to 2040. This time period was chosen because we are more interested in assessing the impact of climate change on water resources in the near future and also because the lowest fractional uncertainty in climate projections is the future 30-50 years (Cox and Stephenson, 2007).

Soil and Water Assessment Tool (SWAT) is an integrated semi-distributed hydrological model, which includes a plant growth module. Procedures to describe the effect of $\mathrm{CO} 2$ concentration, precipitation, temperature and humidity on plant growth, evapotranspiration, snow, and runoff generation make the program a valuable tool for the investigation of climate change impacts (Arnold, 1998). SWAT has been used in many international applications (Gassman et al., 2007; Faramarzi et al., 2009; Schuol et al., 2008) to quantify the impact of land management practices on water, sediment, and agricultural chemical yields in large complex watersheds with varying soils, landuses and management conditions over long periods of time. In this study, we used SWAT to specifically investigate the impact of climate variability on precipitation and evapotranspiration distribution, river discharge and soil moisture. These variables were then used to quantify the changes in water resources with respect to blue water (river discharge plus aquifer recharge) and green water (soil moisture and evapotranspiration). The impact assessment was quantified at the subbasin scale using a series of anomaly maps (\% deviations from historic data). To quantify the impact of climate change on water resources availability, we used the ensemble of simulations from 5 global climate models (GCMs): HadCM3, PCM, CGCM2, CSIRO2, and ECHAM4, and four IPCC (2007) emission scenarios: A1FI, A2, B1, and B2. These GCMs were selected based on data availability to cover a wide range of changes in the global mean temperature. For the SRES scenario A1FI, the CSIRO2 and HadCM3 models can be considered "hot" models with temperature increases of up to $5.5^{\circ} \mathrm{C}$ until the year 2100. PCM is rather "cold" with a maximum increase of $3.5^{\circ} \mathrm{C}$ until 2100 . CGCM2 is in the upper middle with up to $5{ }^{\circ} \mathrm{C}$ (Mitchell, et al., 2004). This resulted in 18 climate projections (for ECHAM4, only A2 and B2 were simulated). The future climate data were then fed to the SWAT model to simulate the changes in different water resources components. The anomalies were calculated as the \% differences between the prediction uncertainties of the 18 climate scenarios at the 50\% probability level and averaged over the period of 2020-2040 and those of the historic (1975-1995) period. In addition, the impact of climate change on the frequency and intensity of droughts was also investigated.

The SWAT model used in this investigation was calibrated and validated previously with uncertainty analysis by Schuol et al. (2008) using SUFI2 algorithm of the SWAT-CUP program (Abbaspour et al., 2009; Abbaspour et al., 2011) (http://www.eawag.ch/forschung/siam/software/swat/index). The prediction 
uncertainty in this hydrologic model reflects the combined uncertainties of input, model structure, and parameters, but excludes the uncertainties stemmed from different GCMs.

\section{RESULTS}

\subsection{Impact of climate change on different freshwater components}

Figure 1a shows the average values of blue water (mm yr-1) based on the historic data of 1975-1995. The projected effects of climate change are shown in Figure $1 \mathrm{~b}$ as the anomaly map based on the averages of the prediction from the 18 climate scenarios. Generally, blue water will increase in the southern part of the continent except in the very dry southern border and south west coastal areas of South Africa and Namibia. An increase of up to 400 percent in these regions, however, might not bring a significant increase in blue water resources availability because of the very low basis. The countries located in the Horn of Africa and Sahel will suffer from decrease of blue water resources by 25 to 100 percent while moving to the northern arid and hyper arid countries, an increase of up to 25 to 400 percent might have a large eco-hydrological impact. Figure 1c illustrates the coefficient of variation of the historic blue water resources. Blue regions are more reliable in terms of their water resources from year to year. Comparison of the historic coefficient of variations of blue water resources with that of the future (Figure 1d) shows that inter annual change of blue water resources availability is more or less similar to the past in most of the central and northern parts while it shows an increase in southern semi-arid and arid areas, implying less reliability in the blue water increases in these regions.
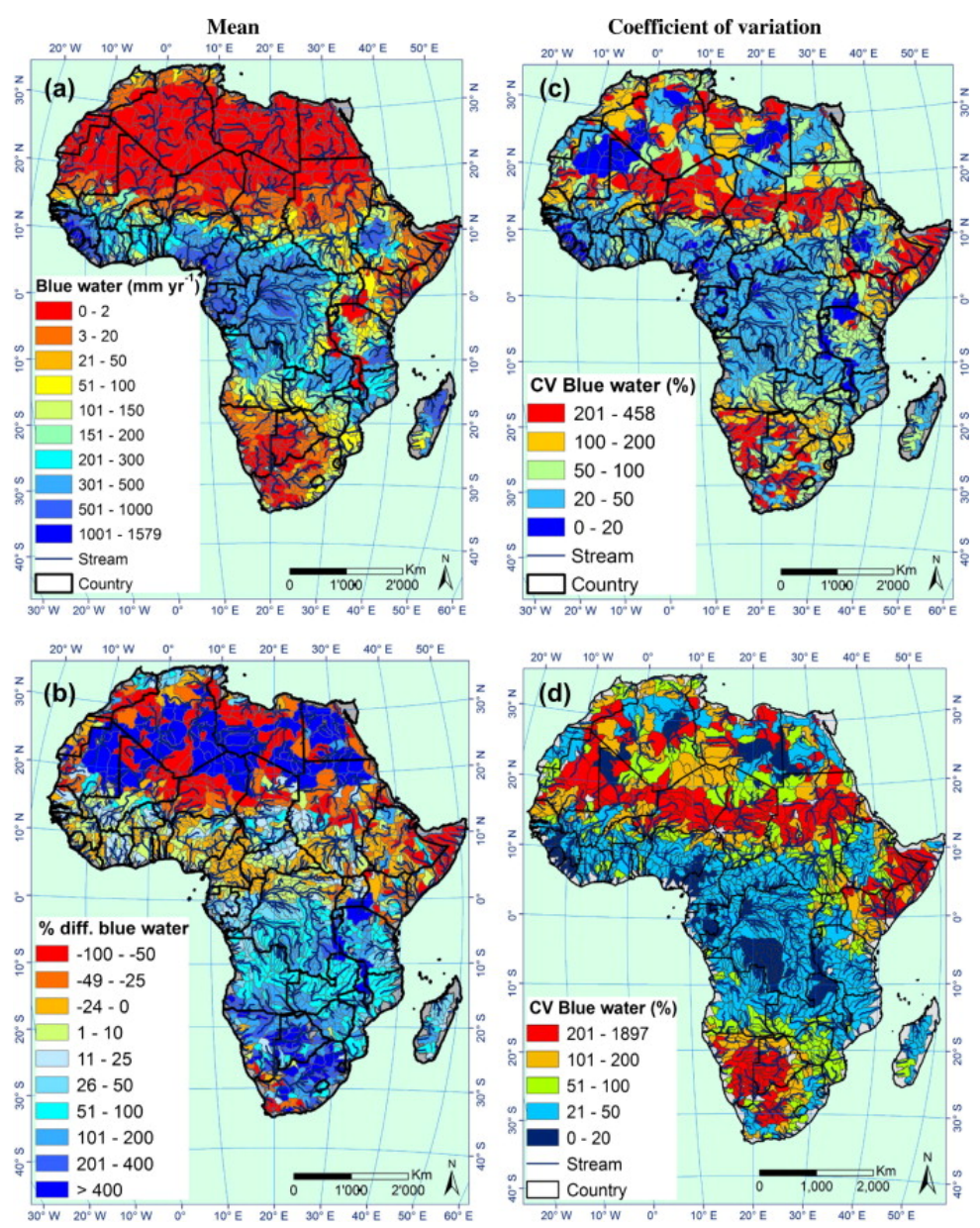

Figure 1. Blue water spatial pattern of mean (a), and coefficient of variation (c) of blue water resources which are calculated based on the average annual M95PPU (i.e. 50th percentile out of 200 simulations) values during 1975-1995 period, anomaly map which is the \% difference calculated based on the data period 2020-2039 from the 1975 to 1995 (b), and coefficient of variation of blue water during 2020-2039 (d) for which the predictions of 18 scenarios from five GCMs are considered. 
In Figure 2, the long term average annual green water storage (soil moisture) is shown for the past and future periods along with their coefficient of variations. There are significant spatial discrepancies in soil water availability and changes in the future. Southern part of Africa shows an increase in soil water with a larger reliability than the blue water resources. Although in Figure $2 \mathrm{~b}$ a larger soil moisture is predicted, its reliability is quite low as indicated in Figure $2 \mathrm{~d}$.
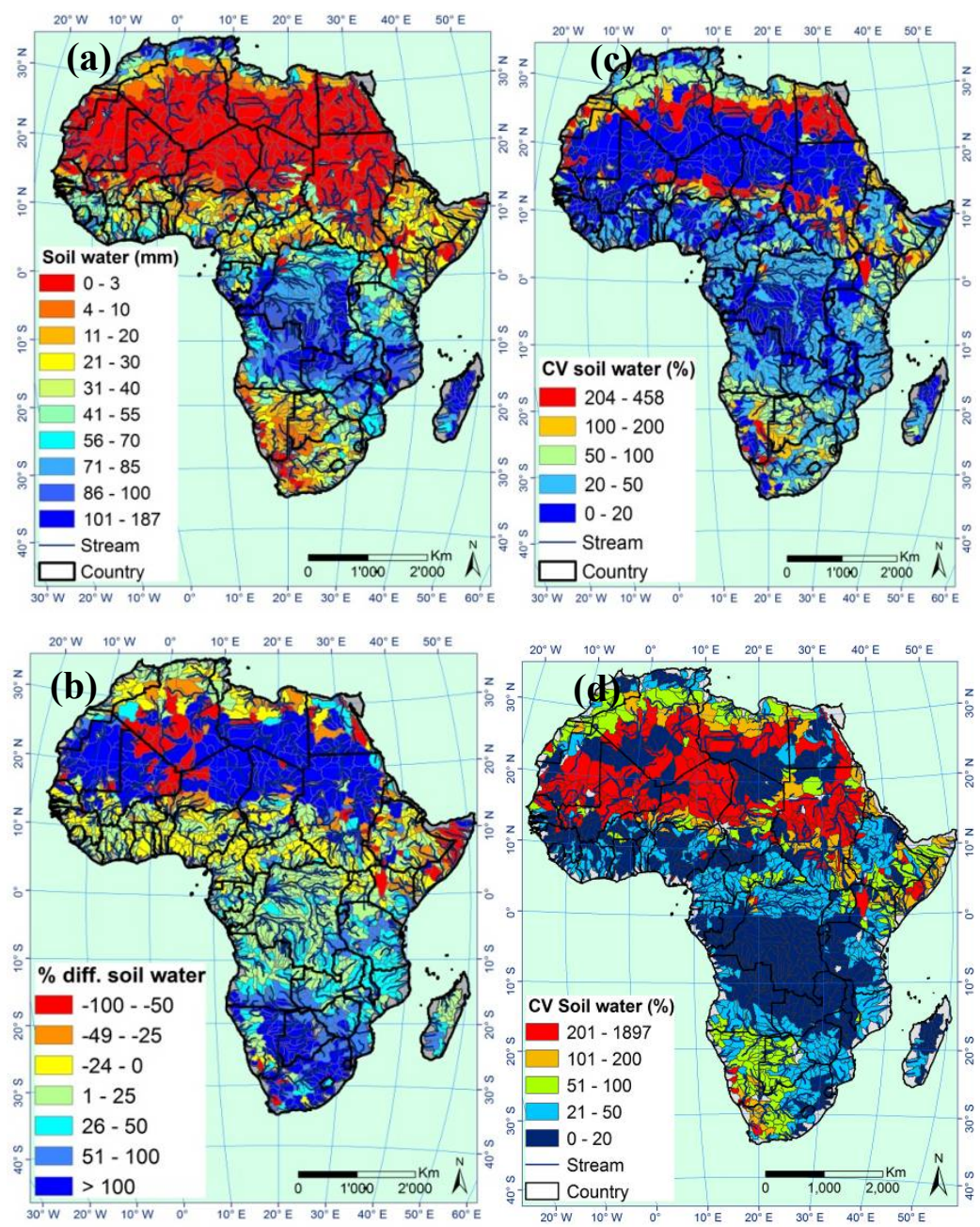

Figure 2. Green water spatial pattern of mean (a), and coefficient of variation (c) of green water storage which are calculated based on the average annual M95PPU values during 1975-1995 period, anomaly map which is the \% difference calculated based on the data period 2020-2039 from the 1975 to 1995 (b), and coefficient of variation of soil water during 2020-2039 (d) for which the predictions of 18 scenarios from five GCMs are considered all together.

\subsection{Impact of climate change on the duration of dry and wet periods}

To investigate the impact of climate change on flooding and drought we selected seven subbasins from different climatic conditions in Africa. The average distribution of the number of days with precipitation $>2$ $\mathrm{mm} \mathrm{d}-1$ and precipitation $>10 \mathrm{~mm} \mathrm{~d}-1$ for these regions during 1975-1995 and 2020-2040 are shown in Figure 3. Most scenarios indicate that the hyper arid region of southwestern Egypt (Figures 3a,b) as well as the semi arid region of northern Kenya (Figures 3e,f) experience larger number of days with precipitation $>2$ $\mathrm{mm} \mathrm{d}-1$ in spring months. This is true for the summer months of the arid region of southern Niger (Figures $3 c, d)$. In the arid regions of South Africa, the northern region shows the largest increase in the number of wet days in winter and spring months for both $>2$ and $>10 \mathrm{~mm} \mathrm{~d}-1$ rainfall events (Figures $3 \mathrm{k}, 1)$. This is corroborated by all scenarios. In the southern parts of South Africa (Figures $3 \mathrm{~m}, \mathrm{n}$ ), all scenarios indicate a decrease in the number of days with precipitation $>2 \mathrm{~mm} \mathrm{~d}-1$ in the winter and spring months, along with an increase in the summer months. 
In humid and semi humid regions, the number of wet days is projected to increase in most of the months (Figures 3g-j). The number of days with larger rainfalls, precipitation $>10 \mathrm{~mm} \mathrm{~d}-1$, is not increased significantly in both humid and semi humid regions. However, the small changes in the number of wet days in the arid and semi-arid regions are unlikely to bring about important consequences to water conditions.

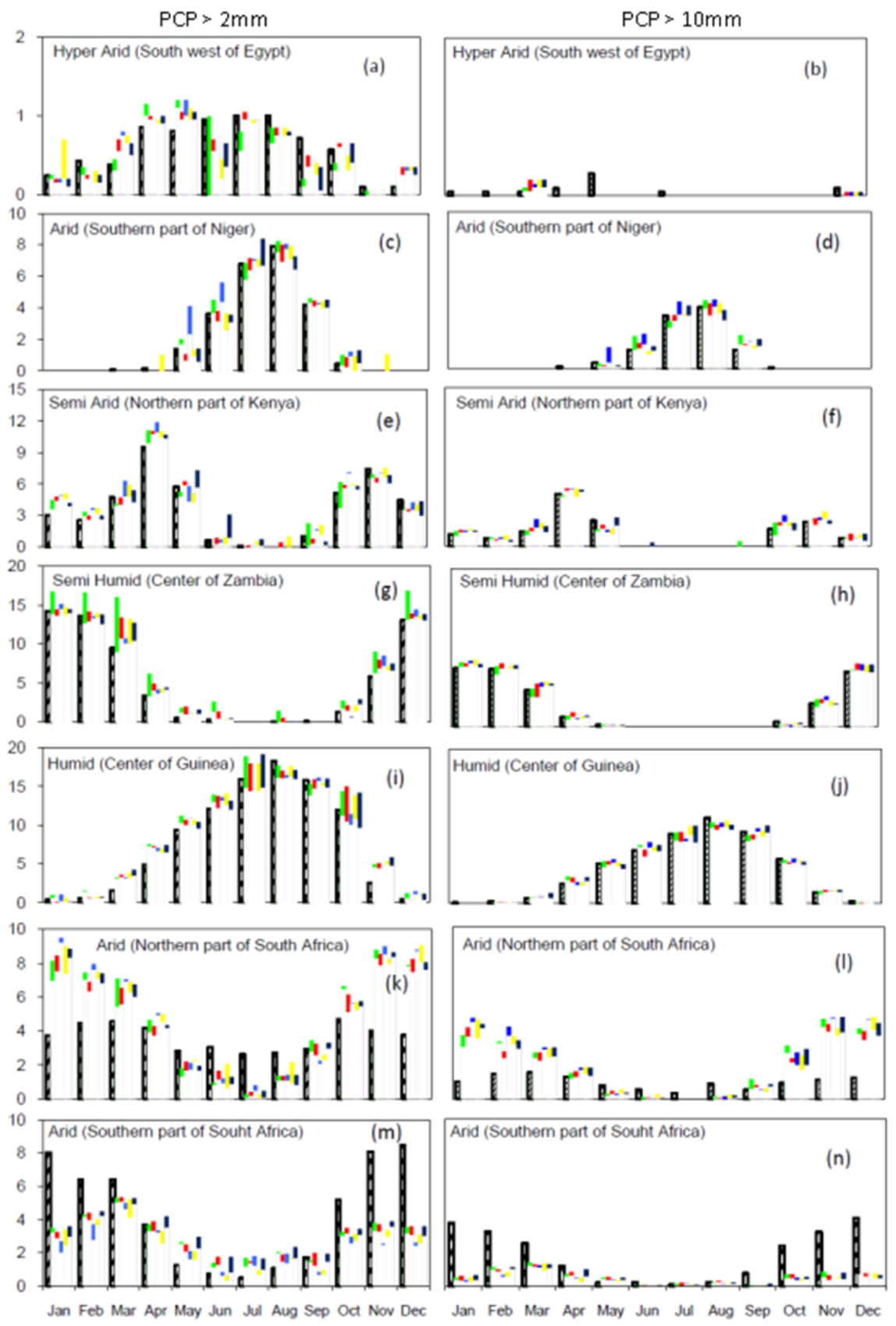

Figure 3. Comparison of the number of wet days between historic (1975-1995), presented with dashed columns and future (2020-2039) periods for subbasins selected from different climatic regions. The colored bands show the range of predictions resulted from different scenarios in each GCM (CGCM2: green, CSIRO: red, ECHAM: blue, HADCM3: yellow, PCM: black,). In these graphs a wet day is defined as a day with precipitation $>2 \mathrm{~mm}$ (left column), and $>10 \mathrm{~mm}$ (right column).

To draw a clearer picture of the changes and severity of the dry periods in Africa, we produced Figure 4 . It shows the number of consecutive days with rainfall $<2 \mathrm{~mm} \mathrm{~d}-1$. The numbers of such periods were counted for the duration of 20 years in the past (1975-1995) and the future (2020-2040) using all 18 scenarios and averaged. Figure 4 shows the recurrence times and the average length of dry periods. In general, the duration of dry periods increases in the future in the north and in the south, while the central Africa and regions in southeast experience shorter duration of dry periods. 

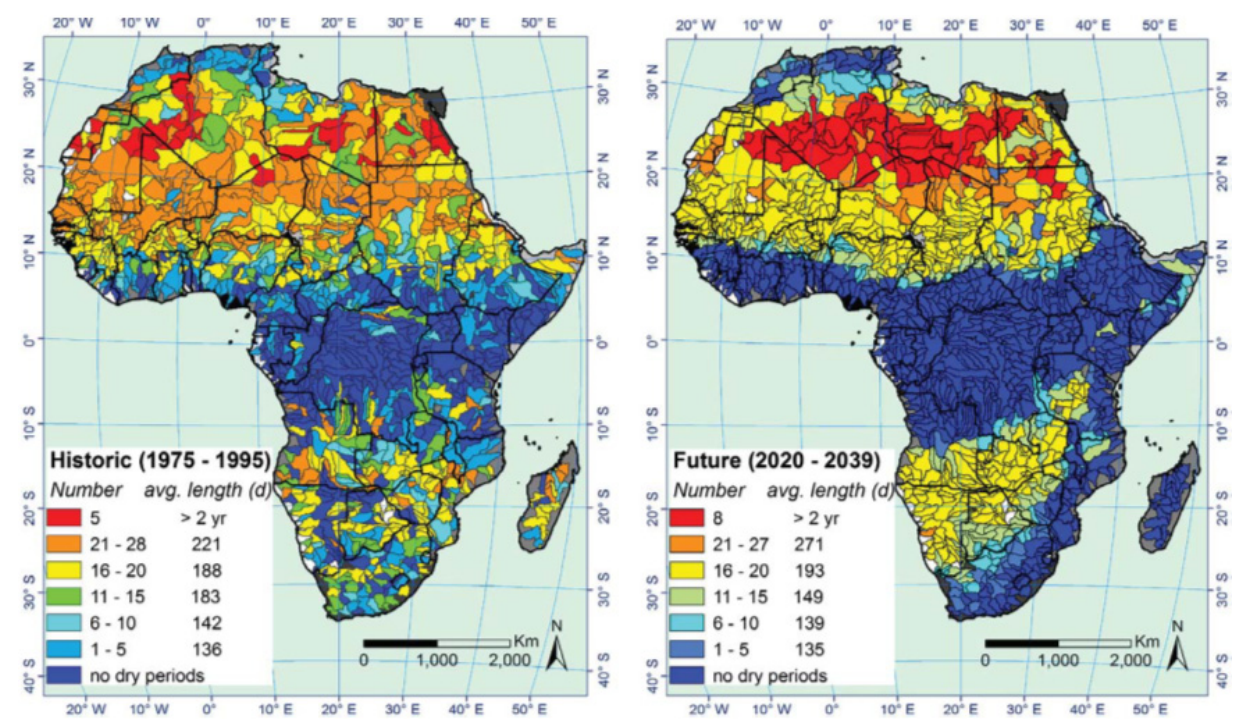

Figure 4. Comparison of the number of drought events (left column in the legend) and the average drought length (right column in the legend) for historic and future scenarios.

\section{DISCUSSION AND CONCLUSIONS}

\subsection{Impacts of climate change on freshwater components}

In Africa, a large variation has been reported with respect to temperature, precipitation and climate conditions across the regions in the continent. These spatial and temporal climate variations exert a significant impact on the economic development of Africa, particularly for the agricultural and waterresources sectors, at regional and local scales (IPCC, 2007). In semi arid regions of the Sahel, Horn of Africa, and Southern part of Africa, large rural and urban communities depend on water availability for rainfed and irrigated agriculture, as well as bio-mass derived energy. Their water supplies are often insecure and may be dependent on local rivers or groundwater. Climate change is expected to pose a serious impact on their agricultural systems and crop productivity. As shown in this study, climate change will lead to increased climatic variability and decrease of blue and green water resources in these regions. These will likely put the local communities at a higher risk. The scale of the impact could be large due to the size of the affected population, the vulnerability of the poor farmers, and the lack of adaptive institutional capacity to manage the impacts.

\subsection{Implications of climate change for drought and flood}

Water-related aspects of climate, such as droughts, floods and desertification have serious implications for African countries' development. Drought is one of the most frequent climate-related phenomena occurring across large portions of the African continent, often with devastating consequences for the agricultural production and food security. In the countries of southern and eastern Africa situated in semi-arid regions, the rainfed agricultural production is mainly limited by the availability of soil moisture. Heavy rains often do not significantly increase soil moisture, but tend to produce runoff without infiltrating into the soil. The problems are aggravated by the tendency of prolonged dry periods to occur at irregular intervals. As projected in this study, the eastern and some southern regions of the continent will experience lesser rainfalls, smaller blue water and green water availability (Figures 1 and 2, respectively), and longer periods without a major rainfall event (Figure 3) combined with larger annual variations. Hence they are susceptible to more severe drought conditions. 


\section{REFERENCES}

Abbaspour, K.C. (2011). User manual for SWAT-CUP, SWAT calibration and uncertainty analysis programs, 103 pp., Eawag: Swiss Fed. Inst. of Aquat. Sci. and Technol., Duebendorf, Switzerland. Available at: http:/wwww.eawag.ch/organisation/abteilungen/siam/software/swat/index EN

Abbaspour, K.C., Faramarzi, M., Ghasemi, S.S. Yang, H. (2009). Assessing the impact of climate change on water resources in Iran, Water Resour. Res., 45, W10434, doi:10.1029/2008WR007615.

Arnold JG, Srinivasan, R, Muttiah, R.S., Williams, J.R. (1998). Large area hydrologic modeling and assessment - Part 1: Model development. Journal of the American Water Resources Association 34: 7389.

Boko, M., Niang, I., Nyong, A., Vogel, C., Githeko, A., Medany, M., Osman-Elasha, B., Tabo, R., Yanda, P., 2007. Africa climate change 2007: impacts, adaptation and vulnerability. In: Parry, M.L., Canziani, O.F., Palutikof, J.P., van der Linden, P.J., Hanson, C.E. (eds), Contribution of working group II to the fourth assessment report of the intergovernmental panel on climate change, Cambridge University Press, Cambridge, pp 433-467.

Falkenmark, M., Rockstrom, J. (2006). The new blue and green water paradigm: Breaking new ground for water resources planning and management, Journal of Water Resources Planning and Management, 132, 129-132.

Faramarzi, M., Abbaspour, K.C., Schulin, R., Yang, H. (2009). Modelling blue and green water resources availability in Iran. Hydrol. Process., 23, 486-501.

Gaiser, T., Judex, M., Igue A.M., Paeth, H., Hiepe, C. (2011). Future productivity of fallow systems in SubSaharan Africa: is the effect of demographic pressure and fallow reduction more significant than climate change?, Agricultural and Forest Meteorology, 151, 1120-1130.

Intergovernmental Panel on Climate Change (IPCC) (2007). Climate Change 2007: Impacts, Adaptation, and Vulnerability, Contribution of Working Group II to the Third Assessment Report of the Intergovernmental Panel on Climate Change, edited by M. L. Parry et al., Cambridge Univ. Press, Cambridge, U. K.

Liu, J., Fritz, S., van Wesenbeek, C.F.A., Fuchs, M., You L., Obersteiner, M., Yang, H. (2008). A spatially explicit assessment of current and future hotspots of hunger in sub-Saharan Africa in the context of global change, Global and Planetary Change 64: 222-235.

Milly, P.C.D., Dunne, K.A., Vecchia, A.V., 2005. Nature 438 (17), 347-350.

Schlenker, W., Lobell, D. B. (2010). Robust negative impacts of climate change on African agriculture, Environ. Res. Lett. 5, 014010.

Shongwe, M.E., van Oldenborgh, G.J., van den Hurk, B.J.J.M., de Boer, B., Coelho, C.A.S., van Aalst, M.K. 2009. Projected Changes in Mean and Extreme Precipitation in Africa under Global Warming. Part I: Southern Africa. Journal of Climate. 22, 3819-3837.

Schuol, J., Abbaspour, K. C., Srinivasan, R., Yang, H. (2008). Modelling blue and green water availability in Africa, Water Resour. Res., 44, W07406, doi:10.1029/2007WR006609.

Vörösmarty, C. J., McIntyre, P.B., Gessner, M.O., Dudgeon, D., Prusevich, A., Green, P., Glidden, S., Bunn, S.E., Sullivan, C. A., Reidy Liermann,C., Davies, P.M. (2010). Global threats to human water security and river biodiversity, Nature, 467, 555-561. 